\title{
Swelling of the leg, deep venous thrombosis and the piriformis syndrome
}

\author{
Sara Bustamante FRCA, Peter G Houlton FRCA FRCPC
}

\section{S Bustamante, PG Houlton.}

Swelling of the leg, deep venous thrombosis and the piriformis syndrome.

Pain Res Manage 2001;6(4):200-203.

BACKGROUND: The piriformis syndrome, which was first described 60 years ago, is a well recognized cause of sciatica, leg pain and low back pain, due to the entrapment of the sciatic nerve in the piriformis and other rotator muscles. Very few complications relating to this syndrome have been described.

AIMS: To discuss how the piriformis syndrome may cause venous engorgement in the lower limb, and how the piriformis syndrome should be included as a possible cause of acute deep venous thrombosis in a not initially swollen leg. Both complications can occur independently.

METHODS: Two cases of swelling of the leg and acute deep venous thrombosis independently associated with the piriformis syndrome are presented.

CONCLUSIONS: Swelling of the leg and deep venous thrombosis are possible complications of the piriformis syndrome that occur due to entrapment of nerves and vessels within the leg, secondary to a severe spasm and hypertrophy of the piriformis and other rotator muscles.

Key Words: Low back pain; Piriformis syndrome; Sciatica

\section{Enflure des jambes, thrombose veineuse pro- fonde et syndrome du pyramidal}

CONTEXTE : Le syndrome du pyramidal, décrit pour la première fois il y a 60 ans, est bien connu pour être cause de sciatique, de douleurs aux jambes et de lombalgies basses en raison de la compression du nerf sciatique dans le muscle pyramidal du bassin et les autres muscles rotateurs du dos. La documentation fait état de très peu de complications du syndrome.

OBJECTIFS : Voir comment le syndrome du pyramidal peut causer une congestion veineuse dans les membres inférieurs, puis figurer parmi les causes possibles de thrombose veineuse profonde aiguë dans des jambes non enflées au départ. Les deux complications peuvent se produire indépendamment.

MÉTHODE : Présentation de deux cas d'enflure des jambes et de thrombose veineuse profonde aiguë, associés indépendamment au syndrome du pyramidal.

CONCLUSION : L'enflure des jambes et la thrombose veineuse profonde sont des complications possibles du syndrome du pyramidal en raison de la compression des nerfs et des vaisseaux dans les membres inférieurs, secondaire à un spasme important ou à une hypertrophie du muscle pyramidal du bassin et des autres muscles rotateurs du dos.
$\mathrm{T}$ he term 'piriformis syndrome' was first used by Robinson (1) in 1947. The six cardinal features of this syndrome were history of trauma to the sacroiliac and gluteal region; pain in the region of the sacroiliac joint, greater sciatic notch and piriformis muscle, extending down the leg and causing difficulty in walking; acute exacerbation of pain brought on by stooping or lifting that is moderately relieved by traction; palpable sausage-shaped mass over the piriformis muscle that is tender to palpation; positive Lasegue sign; and possible gluteal atrophy (2).
An estimated $6 \%$ of the sciatica seen in general practice is thought to be caused by the piriformis syndrome (2). The piriformis and other short, adjacent synergists rotator muscles, such as the quadratus femoris, gemelli, obturator internus and obturator externus muscles, and others such as the levator ani and coccygeus, are involved in the syndrome (3). Severe spasm and hypertrophy of these muscles result in entrapment of the sciatic nerve and adjacent structures at the greater sacral foramen, causing swelling, inflammation, and sciatic, buttock and leg pain $(3,4)$. 
Some of the complications associated with this syndrome are 'hip pocket neuropathy' or 'wallet neuritis' due to piriformis pain associated with sitting on hard surfaces (5); pain with bowel movements $(3,6)$; dyspareumia in women $(6)$; pain, numbness and paraesthesia at the lateral scrotum in men and the labia majora in women $(2,3)$; lumbosacral radiculopathy due to S1 compression (3); and swelling of the lower limb $(2,3)$.

We describe two cases. In the first, the swelling of the leg was diagnosed as a complication of the piriformis syndrome. However, up to that point it had been considered to be a deep venous thrombosis (DVT), which was never confirmed. In the second case, acute DVT was a possible complication of the piriformis syndrome, in the presence of a not previously swollen leg. For both cases, we discuss how the piriformis syndrome may cause venous engorgement in the lower limb, and how the piriformis syndrome should be included as a possible cause of acute DVT. These can be two independent complications of the same syndrome.

\section{CASE PRESENTATIONS}

\section{Case 1}

A 63-year-old man was referred by neurologists to the chronic pain clinic of the Anaesthetic Department of St Peter's Hospital, Surrey, United Kingdom. He suffered from mild spastic paraparesis and a swollen left leg, and was diagnosed with myofascial pain syndrome affecting the piriformis muscle. At the same time, the piriformis syndrome was causing symptoms and signs of left lumbar 5 (L5) nerve root entrapment; as a consequence, there were signs of complex regional pain syndrome type II in the left leg. Seven months before the referral, the patient had collapsed when he stood up from a chair, having suffered a few days before from several hypertensive episodes. When he stood up from the chair, he felt a tearing sensation over the lateral aspect of the left calf. Over the next few days, the pain spread up his leg to an epicentre adjacent to the left buttock. He developed persistent pain in his leg and was unable to sit comfortably or walk. Shortly after the event, he developed acute swelling of the left calf; therefore, he was investigated for a possible DVT. The investigations (venogram and V/Q scan) were inconclusive. The left leg remained swollen to some extent, but less severely than it had been. His spasticity was due to bilateral cerebral infarcts and mild cervical myelopathy, which were seen on magnetic resonance imaging (MRI) of the head, which he underwent as part of the overall investigations regarding his collapse. He also underwent a carotid Doppler test and echocardiography to rule out any other possible differential diagnoses. Results of both tests were within normal ranges. The neurologist had also investigated his symptoms of root entrapment over the L5 distribution (pain over the lateral aspect of the calf and numbness over the left big toe) with a lumbar MRI, which showed degenerative changes of the lumbar spine, and no thecal or nerve root compression.

On examination, he had extreme tenderness over the left buttock and a positive piriformis stretching test (painful and limited passive medial rotation and adduction of the affected side, with a flexed left thigh $60^{\circ}$ at the hip). He had a slightly swollen leg and a very stiff, edematous left foot. There were signs of vasodilation, and from the middle of the leg to the foot, there was a subjective increase in temperature on palpation by the investigator. There was some sensory dysfunction of the limb, with hyperalgesia of the left knee and subjective numbness over the left toe. The patient also had discomfort across the lateral aspect of the calf and subjective weakness of the left ankle. The skin of the limb looked thin and shiny, with patchy areas of decreased colour compared with the other leg. During the neurological examination, results of the straight leg raise test were $50^{\circ}$ for the right leg and $10^{\circ}$ for the left leg. On the left side, the femoral stretch test was positive and ankle reflex was decreased; he had sustained clonus in both ankles with decreased bilateral plantar reflexes. He also suffered from high levels of anxiety (7) and depression (8) according to the hospital anxiety and depression scale.

The patient had been treated with different analgesics and physiotherapy, but the pain had not resolved. He was treated with two left piriformis compartment blocks under $\mathrm{x}$-ray control and piriformis muscle stretching exercises to be performed at home. The blocks were administered six weeks apart. The first block consisted of ropivacaine $0.2 \% 15 \mathrm{~mL}$ with methylpredisolone $40 \mathrm{mg}$ (Depo-medrone, Pharmacia \& Upjohn, United Kingdom). The patient improved substantially; he was able to walk for the first time in months, and the swelling in his leg and foot were nearly absent. After receiving a second block of ropivacaine $0.2 \% 20 \mathrm{~mL}$ with $100 \mathrm{U}$ of botulinum toxin, he had some discomfort in the left buttock for four days, which subsequently resolved. After the second block, the swelling was almost completely abated, and there was an enormous improvement in his depressive symptoms. His follow-up continued for three months; during this time, the weakness of his knees improved, and he received physiotherapy to strengthen his quadricep muscles.

\section{Case 2}

A 78-year-old woman was referred by an orthopedic surgeon to the chronic pain clinic of the Anaesthetic Department of St Peter's Hospital, suffering from chronic lumbosacral back pain and lumbar muscle spasms due to severe osteoarthritis. She had been born with a congenitally dislocated hip, and had received bilateral hip and knee replacements. She had complained of dull pain in the lumbosacral region, radiating upwards, but not into her legs, for the past two years. The pain was worse when walking and standing, and relieved by sitting.

On examination, she had an abnormal gait due to the differing length of the legs and scoliosis. The pain was worse on extension and rotation of the lumbar sacral spine, and she had tenderness in the piriformis trigger points and during the piriformis stretching test (painful and limited passive medial rotation and adduction of the affected side, with the thigh flexed $60^{\circ}$ at the hip). She also had a number of trigger points in the upper and lower parts of her body. Power and sensation were preserved in both legs, with no signs of radiculopathy. However, left ankle reflex was absent, which had been the 
case for a while. She was diagnosed with bilateral piriformis compartment syndrome and bilateral lumbar facet joint dysfunction, despite the possibility that the piriformis trigger points and stretching tests were falsely positive due to her hip pathology. The positive response and recovery of the patient to the treatment contributed to the final diagnosis.

She was started on imipramine $10 \mathrm{mg}$, which was to be increased to $25 \mathrm{mg}$ after one week if tolerated. Bilateral facet joint injections, bilateral ileopsoas and piriformis compartment blocks were also performed. All these blocks were performed in addition to piriformis muscle-stretching exercises. During her facet joint injections, only one on the right side, L4/5, was injected with prilocaine $0.2 \% 1 \mathrm{~mL}$ and some Depo-medrone, under contrast and $\mathrm{x}$-ray control. L3/4 on the same side caused too much pain down the leg to be injected and was, therefore, abandoned. L5/S1 on the right side and none of the lower lumbar facet joints on the left side could be identified and, therefore, were not injected. Both ileopsoas muscles were confirmed at the level of L4 transverse process, with omnipaque contrast and $\mathrm{x}$-ray screening. Each was injected with bupivacaine $0.25 \% 10 \mathrm{~mL}$ and Depo-medrone $20 \mathrm{mg}$. The piriformis compartment was identified under contrast and $\mathrm{x}$-ray control, and prilocaine $0.2 \% 10 \mathrm{~mL}$ and Depomedrone $20 \mathrm{mg}$ were injected into each one.

On the day of her treatment, the patient was noted to be in atrial flutter, for which she was referred and subsequently discharged by the medical team, after imipramine treatment had been stopped, and her electrolyte levels and thyroid function had been tested. She was to be followed up by the cardiologist in the clinic after four weeks, and was to undergo further treatment if she had not reversed to sinus rhythm by then.

The patient was reviewed a month later in the pain clinic, and showed improvement in her pain and mobility after her treatment. Despite having difficulties with the exercises due to knee pain and previous hip replacements, her walking had improved after the blocks. She was referred to the physiotherapists for advise on her exercise regimen. She was still in atrial flutter, with a ventricular rate of 100 beats $/ \mathrm{min}$, and showed clinical signs of DVT in her right leg, with a gradual increase in swelling and pain in her right calf and leg over the previous four days, radiating to the back of the knee and thigh. She was again referred to the medical team and cardiologist. She was investigated with a venogram - which showed popliteal DVT - a V/Q scan and an echocardiogram, with no evidence of pulmonary embolism or thrombus; however, bilateral dilation of both atriums, and mild to moderate mitral and tricuspide regurgitation with good left ventricular function were seen. She was treated with atenolol, digoxin and frumil, and with warfarin for anticoagulation, and refused DC cardioversion.

\section{DISCUSSION}

The piriformis syndrome is often a missed cause of sciatica and pain in the low back, groin, perineum, buttock, hip, posterior thigh and leg, and foot, during defecation and in the rectum (3). Symptoms can be aggravated by the sitting position, by a prolonged combination of hip flexion, adduction and medial rotation, or by activity (3). Patients may complain of swelling in the painful limb and sexual dysfunction $(2,3)$. The incidence is higher in women than in men (ratio 6:1) (9).

Three specific conditions may contribute to the piriformis syndrome: myofascial pain referred from the trigger points in the piriformis muscle, nerve and vascular entrapment by the piriformis muscle at the greater sciatic foramen, and dysfunction of the sacroiliac joint (3).

In the first case, we discuss how the piriformis syndrome may cause, not only nerve entrapment, but also swelling of the leg, possibly by venous engorgement of the lower limb. The second case is an example of why piriformis syndrome should be included as a possible cause of acute DVT, even when an initial swollen leg is not one of the starting symptoms of the syndrome.

The piriformis muscle is a lateral rotator of the thigh when the hip is extended and an abductor when the hip is flexed $90^{\circ}$. It is innervated by S1, S2. Medially, it is attached to the inner surface of the sacrum, and laterally to the greater trocanter of the femur, together with other short lateral rotators (superior gemellus, inferior gemellus, quadratus femoris, obturator internus and obturator externus, which are innervated from L3-S3 $[2,3])$. There are six possible variations of the relationship of the sciatic nerve with the piriformis muscle, which normally lies posterior to the sciatic nerve as it leaves the pelvis through the greater sciatic foramen $(2,3,6,9,10)$. Blood vessels and nerves can become compressed and entrapped between the piriformis muscle and the rim of the greater sciatic foramen, or within the muscle when the muscle is sufficiently enlarged to fill the foramen $(2,3,7,11)$. According to Freiberg (7), there is a rich vascular plexus from the inferior gluteal vessels between the sciatic nerve and the piriformis muscle. Moreover, compression of the sciatic nerve may cause distal venous engorgement of the sheath of the trunk. The vulnerable structures through the greater sciatic foramen are:

- the superior and inferior gluteal nerves and blood vessels, which supply the gluteus medius, minimus and tensor fasciae latae muscles;

- the sciatic nerve, which supplies the skin and muscles of the posterior thigh and most of the leg and foot;

- the pudendal nerve and blood vessels, which supply the external anal sphincter muscle and the skin of the posterior thigh, scrotum and labia majora, and are involved in the innervation of the essential structures for normal sexual function; and

- the inferior gluteal nerve, the posterior femoral cutaneous nerve and the nerves innervating the gemelli, obturator internus and quadratus femoris muscles, which supply all the gluteal sensation and function, anterior perineal sensation and motor function, and nearly all the sensation and motor function of the posterior thigh and calf (3). Compression of the superior and inferior gluteal nerves and vessels explains buttock pain and gluteal muscle atrophy (3). 
Virchow (12) described a classical triad of factors that lead to the development of DVT: stasis, hypercoagulability and vessel damage. The piriformis syndrome may contribute to at least two if not three of these factors. Stasis is explained by the entrapment of nerves and blood vessels, which causes, not only engorgement to the sheath of the nerves (7), but also venous stasis and possible mechanical venous flow obstruction from the lower limb in general. Pain produces disuse and atrophy, which finally creates immobility and further increase in venous stasis. The endothelial damage could be explained by the external compression of the previous structures, leading to chronic inflammation and swelling. Therefore, endothelial damage, together with venous stasis and immobility of the limb, encourage platelet aggregation and clot formation.

The differential diagnoses of popliteal DVT are muscular hemorrhage or trauma, rupture of a popliteal cyst, lymphoedema, popliteal nerve compression, knee arthritis or tendinitis, fractures and occlusive arterial disease (12). Because of the findings from the second case, we would like to include the piriformis syndrome as another possible cause of DVT.

\section{CONCLUSIONS}

Nerve and blood vessel entrapment in the piriformis syndrome may cause engorgement and swelling of structures within the leg. This, in conjunction with other factors such as pain and immobility, may lead to swelling of the leg and, on occasion, to acute DVT with a not necessarily previously swollen limb. In the presence of piriformis syndrome, swelling of the leg and DVT should be considered to be two possible and independent complications.

\section{REFERENCES}

1. Robinson D. Piriformis syndrome in relation to sciatic pain. Am J Surg 1947;73:355-8.

2. Parziale JR, Hudgins TH, Fishman LM. The piriformis syndrome. Am J Orthopaed 1996;25:819-23.

3. Travell JG, Simons DG. Piriformis and other short lateral rotators. Gemelli, quadratus femoris, obturator internus, and obturator externus muscles. In: Travell JG, Simons DG, eds. Myofascial Pain and Dysfunction. The Trigger Point Manual. The Lower Extremities Baltimore: Williams \& Wilkins, 1992:186-214.

4. Hanania M, Kitain E. Perisciatic injection of steroid for the treatment of sciatica due to piriformis syndrome. Reg Anesth Pain Med 1998;23:223-8.

5. Noftal F. The piriformis syndrome. Can J Surg 1988;31:210.

6. Barton PM. Piriformis syndrome: A rational approach to management. Pain 1991;47:345-52.

7. Freiberg AH. Sciatic pain and its relief by operations on muscle and fascia. Arch Surg 1937;34:337-50.

8. Pace JB, Nagle D. Piriformis syndrome. West J Med 1976;124:435-9.

9. Simons D, Travell J. Myofascial origins of low back pain. Postgrad Med J 1983;73:99-108.

10. Beaton LE, Anson BJ. Relation of the sciatic nerve and subdivisions to piriformis muscle. Anat Rec 1937;70:1-3.

11. Hallin RP. Sciatic pain and the piriformis muscle. Postgrad Med J 1983;74:69-72.

12. Virchow RLK. Gesammelte Abhandlungen zur Wissenschaftlichen Medizin. Frankfurt: Von Meidinger Sohn, 1856.

13. Creater MA, Dzau VJ. Vascular diseases of the extremities. In: Wilson JD, Braunwald E, Isselbacher KJ, et al, eds. Harrison. Principles of Internal Medicine, 12th edn. Madrid: Interamericana McGraw-Hill, 1991:1179-87.

\section{Reviewers - 2001}

The following people reviewed one or more articles for Pain Research \& Management in 2001.

The Editor-in-Chief and the Publisher are grateful for the generous contribution of all reviewers

Frank Adams

Gordon JG Asmundson

Kenneth Casey

Richard Catchlove

Terence Coderre

Lucy Gagliese

Marek Gawel

Tom Hadjistavropoulos

Joel Katz

Robert Large

William Lariviere

John Loeser

Mortimer Mamelak

Ronald Melzack

Harvey Moldofsky

Dwight Moulin

Harrison G Pope

Gary Rollman

Michael Salter

Barry Sessle

Bengt Sjolund

Ellen Thompson

Eldon Tunks

Dennis Turk

Peter Watson

\section{ADVERTISERS' INDEX}

Pain Research \& Management is a peer review Journal, financed almost entirely through advertising. The companies advertising in this Journal have recognized the need to support high quality, Canadian, ethical journals, and to promote publishing of Canadian medical research. Pulsus Group, the Canadian Pain Society and the readers of Pain Research \& Management appreciate the support of the following companies for making this issue possible:

Janssen-Ortho Inc

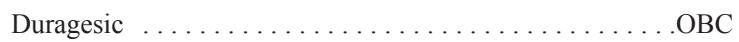

Prescribing information ......................204 Sabex

Hydromorphine Fort . . . . . . . . . . . . . . . 170

Prescribing information ..........................206 


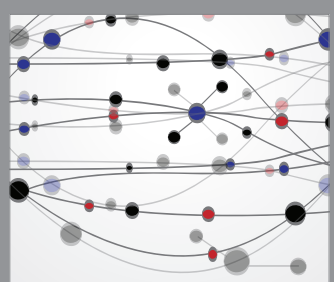

The Scientific World Journal
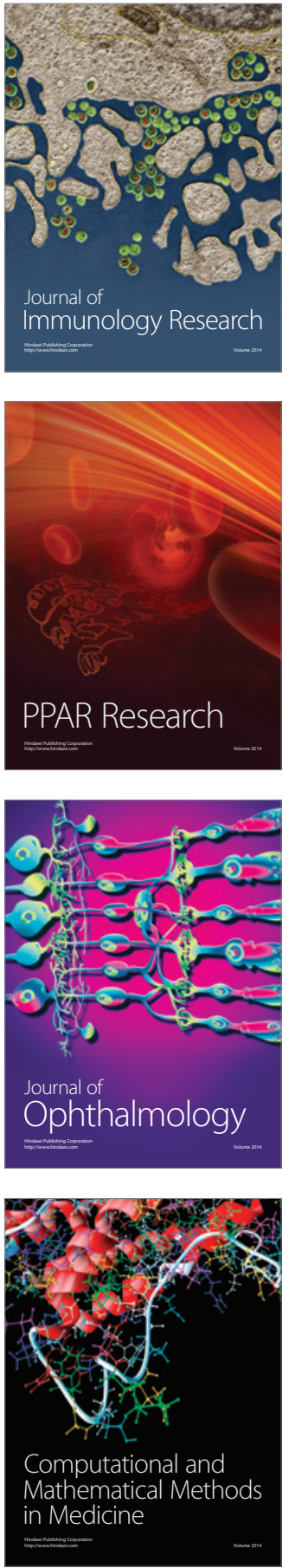

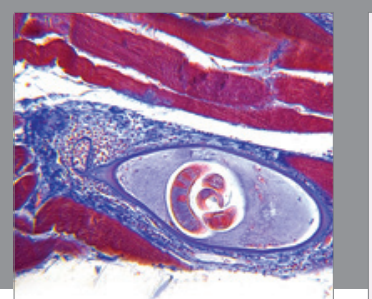

Gastroenterology Research and Practice

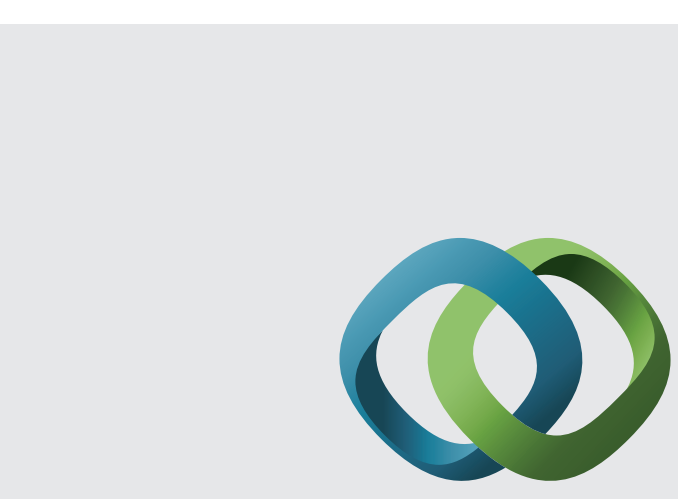

\section{Hindawi}

Submit your manuscripts at

http://www.hindawi.com
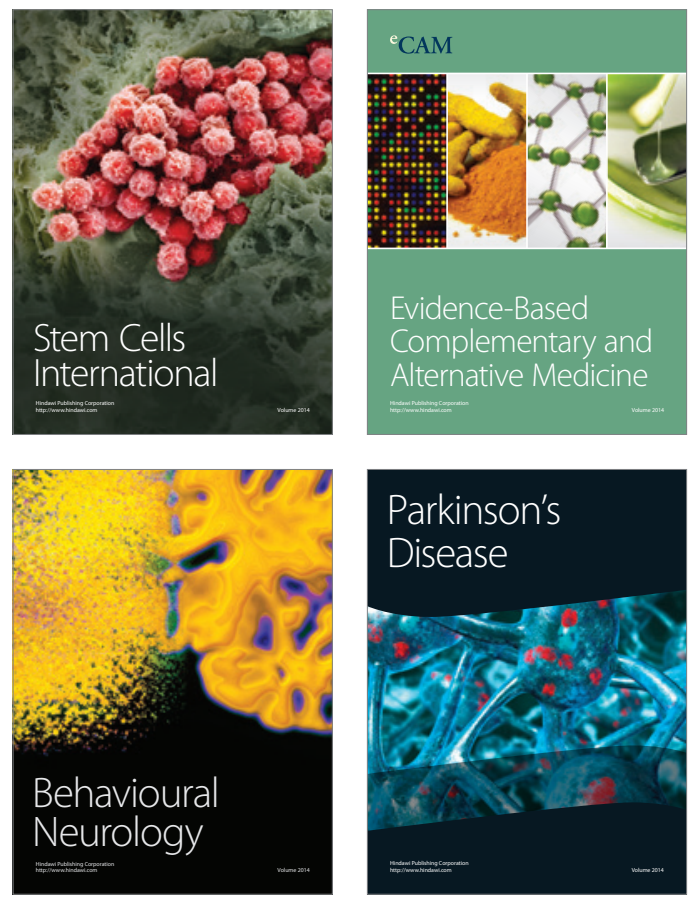
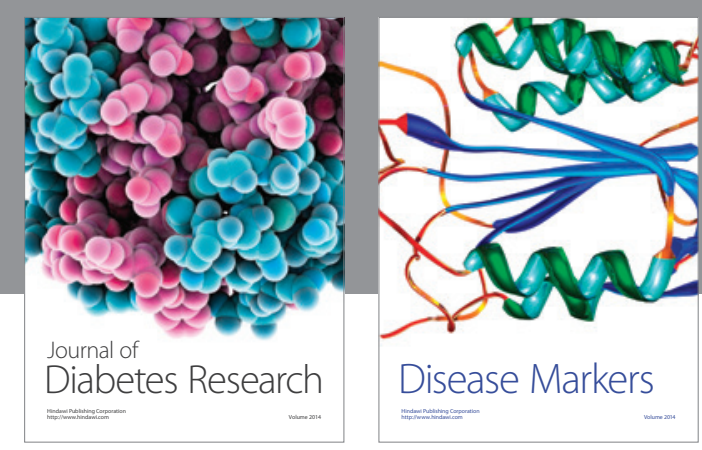

Disease Markers
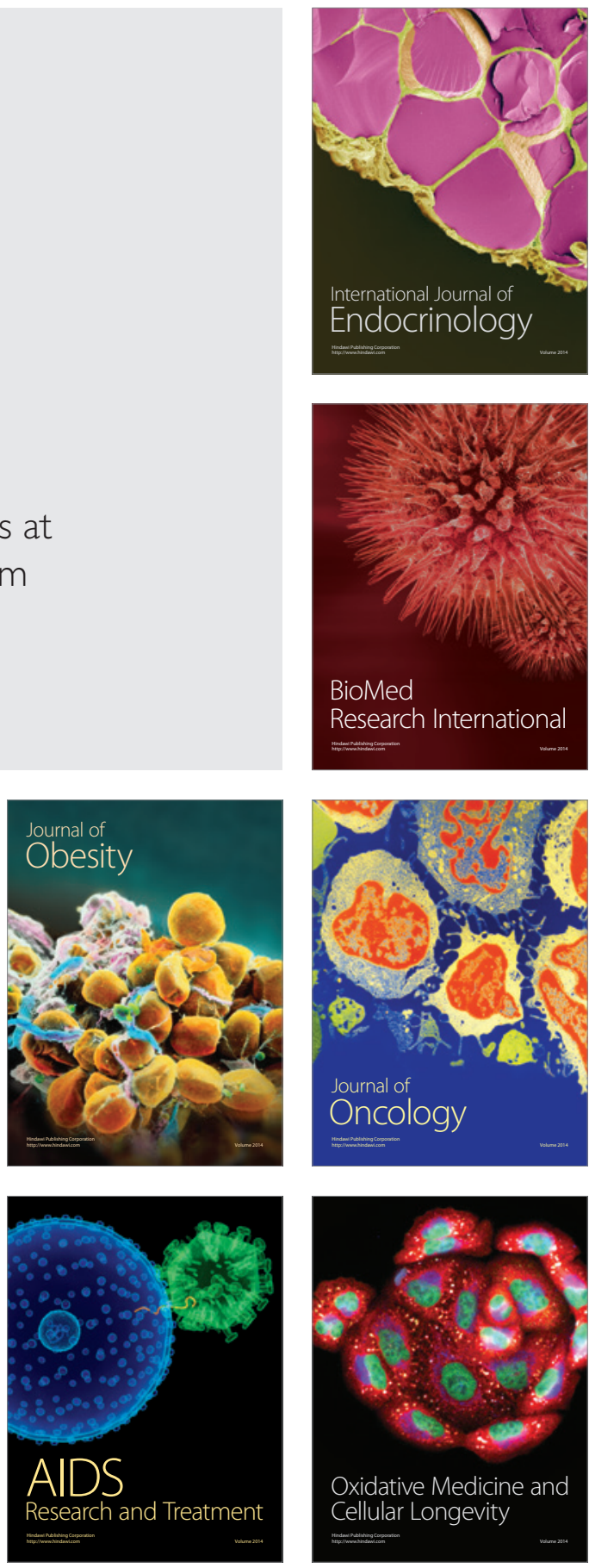